\title{
The Change of Western Cognition of "the Belt and Road" and China's Guiding Strategy
}

\author{
Jiangyue Li \\ Beihai University of Art and Design, Beihai 536000, Guangxi, China \\ Email: 782106101@qq.com
}

\begin{abstract}
The Belt and Road" is a national top-level cooperation initiative proposed by China with the goal of establishing "a community with a shared future for mankind" and transcending geopolitics and ideology to achieve win-win results. Around "the Belt and Road", the West has formed positive cognition such as "Chinese Opportunity", "Channel to Realize Ideal Goals", "Oriental Leading Model", and "Global Sample". However, due to the limitations of "stereotypes" and "zero-sum thinking", some people in the West still have misunderstandings about "the Belt and Road Initiative". To guide them out of cognitive misunderstandings and reduce the cognitive differences between China and the West, we can start from cognitive theory, analyze cognitive performance and its causes, and adopt corresponding strategies and methods.
\end{abstract}

Keywords: "The Belt and Road", cognition, guiding strategy

Due to differences in Chinese and Western cultures and perspectives, it is an indisputable fact that Western scholars, media, and politicians have certain cognitive differences on China's "Belt and Road Initiative". Based on the discourse status of Western countries in the world, their cognition of "the Belt and Road" will inevitably affect the reactions, attitudes, decisions and behaviors of other countries. Although the erroneous cognition of some Western countries have had a certain negative impact on the promotion of "the Belt and Road", the process of the construction of "the Belt and Road" has not slowed down. On the contrary, the remarkable effect of "the Belt and Road" are also conducive to narrowing the cognitive differences between China and the West on "the Belt and Road".

\section{The positive cognition of "the Belt and Road" that is being formed in the West}

"The Belt and Road" is the abbreviation of "the Silk Road Economic Belt and the 21st-Century Maritime Silk Road". "The Belt and Road" borrows the cultural symbols of the "Silk Road" in Chinese history, upholds the principle of "mutual consultation, joint construction, and sharing", adheres to the concept of openness, tolerance, and win-win cooperation, and develops economic cooperation with countries along the route. It is committed to achieving policy communication, facility connectivity, unimpeded trade, financial connectivity, and people-to-people bonds, and jointly building a community of interests, a community of shared destiny, and a community of responsibility for political mutual trust, economic integration, and cultural tolerance. Its ultimate goal is to establish "a community with a shared future for mankind". In today's environment of insufficient global economic power, prevalence of trade protectionism, and significant anti-globalization, the proposal of China's "Belt and Road Initiative" has received widespread positive comments from the international community. Although Western countries have doubts and concerns about the motives, effects and potential impact of China's "Belt and Road Initiative", which has led to many misunderstandings and prejudices, with the continuous progress of "Belt and Road Initiative" and a series of remarkable achievements, there is a "assimilation" and "adaptation" effect in the cognition of western countries, and more and more western countries hold positive cognition.

Generally speaking, the formation of positive cognition of "the Belt and Road" in Western countries presents such a trend. First, from the perspective of analogical horizontal links, take the country as a unit, and expand from the country where the project is located to the surrounding area; extend from the underdeveloped and developing countries where the project is located to developed countries; some developed countries influence each other and affect the major western developed countries, until they affect and drive the cognitive changes in the Western world. Second, from the perspective of the causal vertical links, some countries have realized the transformation from opposition, wait-and-see, and hesitation to cooperation, and the content of cooperation has also changed from infrastructure construction to comprehensive economic and cultural cooperation. Specifically, the current mainstream positive cognition in Western countries include the following three types. 


\section{1 "The Belt and Road" is "China's opportunity"}

Many Western scholars rationally believe that countries around the world should not hesitate to get on the fastdeveloping express train of China. They believe that since the implementation of China's "Belt and Road Initiative", Chinese companies alone have invested more than US\$90 billion in direct investment in countries along the route, which undoubtedly contributed to the infrastructure, finance, trade, transportation, energy supply and other fields of the countries along the route. It has brought huge improvements and upgrades, especially the local employment situation, which has given many backward countries the opportunity and conditions to enter a higher stage of economic and social development. "The Belt and Road" is China's new exploration of globalization under the current international environment. It is the essence of the experience and lessons of China's rapid development over the past half century. The world should take the initiative to accept and integrate into it with a more open attitude. At the same time, more international institutions and non-governmental forces can be included to further expand the scale. Mobilizing the participation of private capital is more conducive to the sustainable development of investment. The realization of this process means that the world today has truly seized China's opportunities.

\section{2 "The Belt and Road" is "a channel to achieve ideal goals"}

Many countries cannot meet the public's demand for public services because of their system and national strength. Henry Tillman, CEO of Grisons Peak in the United Kingdom, believes that since its birth in 2013, Belt and Road Initiative has provided an effective platform for participating countries to meet the needs of public services, as well as closer relations between countries and people. Especially for countries that have plans to vigorously develop infrastructure construction, China's "Belt and Road" has become a channel to achieve ideal goals. ${ }^{[1]}$

For example, Indonesia plans to build 24 terminals, 15 airports, 1,000 kilometers of highways and 35,000 MW power stations from 2015 to 2019, and has launched 13 rounds of economic reform plans since 2016. More open and liberal changes in investment procedures, technology introduction and transfer have been implemented to create conditions to effectively attract domestic and foreign investment and achieve the goal of revitalizing the economy. "The Belt and Road" construction is in line with the development plan of the Indonesian government. Through the construction of basic projects, Indonesia's infrastructure has been effectively improved. ${ }^{[2]}$

\section{3 "The Belt and Road" is the "Eastern leading model"}

Under the Western discourse system, some Western scholars believe that "the West lacks the concept of global history, that is, a broader vision, a broader theme, and a more diverse model". Therefore, at the end of the 20th century and the beginning of the 21st century, the United States and Europe tried their best to maintain their global dominance. This was a catastrophic period. However, "the Belt and Road" has provided a new way of thinking for the world, and it means that a new wave of globalization driven by the East has arrived. This model injects Eastern values into globalization, but at the same time does not reject Western values. The importance of "the Belt and Road" lies in that it avoids the theory of geopolitics and power, provides another choice for the world, provides another vision for a better future, and provides a way to realize the "community with a shared future for mankind".

\section{Misunderstandings of the West on "the Belt and Road Initiative" and the causes}

There are many reasons. First, the West has long dominated the world and formed a mindset centered on the West. The second is that the West demarcates the boundary by ideology, not accepting or even rejecting and suppressing Chinesestyle development logic. The third is the US hegemonic mentality, guarding against the threat of China's development to its own status, and wooing Western countries to choose sides. To correct the Western cognition of "the Belt and Road" and reduce cognitive misunderstandings, we need to understand the cognitive performance and its causes.

\subsection{Stereotypes - "a solution to China's own problems"}

In the stereotype of the West, China is backward. They unilaterally believe that the purpose of China's "Belt and Road Initiative" is to solve the problems China faces at this stage, and they ignore the essence and original intention of China's "Belt and Road Initiative".

China has implemented reform and opening up for more than 40 years, and its economy has achieved unprecedented development and progress. However, there are also many problems in the process of rapid development, such as overcapacity, economic model and economic structure incompatibility. Scott Kennedy, director of the Freeman China Studies Department of the American Center for Strategic and International Studies, believes that the implementation of China's "Belt and Road Initiative" has created opportunities for China to improve its economic and geopolitical situation. 
He believes that the increased demand for Chinese products from participating countries during the development of "the Belt and Road" can help China shift from an existing economic development model to a demand-driven economic development model. In addition, during the construction of "the Belt and Road" project, the financial role played by the AIIB can also enhance the RMB's international financial status.

This cognition ignores the principle of "consulting, co-constructing, and sharing" of "the Belt and Road". China is the advocate and promoter of "the Belt and Road Initiative", and the construction of "Belt and Road Initiative" has brought more development opportunities for all countries. China's promotion of "the Belt and Road Initiative" construction not only focuses on China's own development, but also takes China's development as an opportunity to enable more countries to catch the fast train of China's development and help them achieve their development goals. "The Belt and Road Initiative" emphasizes that while developing one's own interests, more consideration and consideration should be given to the interests of other countries. "The Belt and Road Initiative" embodies China's superb wisdom and value concept of adhering to the correct concept of justice and interests and pursuing harmony and win-win results.

\subsection{Mirror thinking - "China's Marshall Plan"}

A common misunderstanding in the West is to equate "the Belt and Road" with the "Marshall Plan" of the United States. Because people lack a comprehensive understanding of the historical background and content of the "Marshall Plan", this cognition is very deceiving, and even some scholars in China agree. This kind of false cognition comes from mirror thinking, which is simply looking for a comparison object within the scope of self-cognition to characterize things.

The so-called "Marshall Plan" is also called the European Rejuvenation Project. It is a plan of the United States to provide economic assistance and assistance in reconstruction to Western European countries destroyed by the war after World War II. It has a profound impact on the development of European countries and the world political structure. Many Western scholars compare "the Belt and Road" to the "Marshall Plan". For example, Sylvia Tiezzi, editor-in-chief of the Italian Diplomat magazine, believes that the two have four things in common. First, these two plans are to solve the problem of overcapacity through overseas cooperation; second, both of them can help sponsors to enhance the international financial status of their currencies; third, these two policies effectively use their own foreign exchange reserves to increase overseas investment; fourth, these two policies contain a large number of global infrastructure construction plans, and there are big countries at that time as investors. ${ }^{[3]}$

This type of misconception only sees the superficial similarities between "the Belt and Road" and the "Marshall Plan", but ignores the essential differences between the two. First, there are huge differences in cooperation models. Second, there are obvious differences in political goals. The "Marshall Plan" attached harsh political conditions and excluded socialist countries and the vast third world countries. Through comparison, it is not difficult to find that the West superficially applies the "Marshall Plan" cognition to "the Belt and Road", which has caused serious misunderstanding of "the Belt and Road" in Western academic circles and people. In fact, China's development has benefited from the international community and is willing to provide more public products to the international community. China's "Belt and Road Initiative" aims to share China's development opportunities with countries along the route and achieve common prosperity.

\section{Strategies and methods to guide the West's cognition of "the Belt and Road"}

The formation and change of cognition is a complicated and difficult process with certain regularity. To guide the West to get rid of cognitive misunderstandings and correctly understand "the Belt and Road", we should follow the laws of cognition and adopt appropriate strategies and methods.

\subsection{Guide the West to pay attention to the positive impact of China's "Belt and Road" on the regional economy, and enhance the analogical cognition of horizontal links}

Western scholars focus more on the single analysis of what "the Belt and Road" brings to China under the realist theory, but they have not paid more attention to its extensive significance, especially its positive impact on participating countries and regional economies. China's "Belt and Road" is based on trade, which not only resolves internal economic contradictions, but also promotes the development and construction of other countries, effectively realizing the global allocation of resources, and is a mutually beneficial and win-win model. First, "the Belt and Road" has created a platform for labor circulation. Especially in the context of the rapid decline in the global labor force and the slowdown of economic development, it provides a guarantee for infrastructure construction projects that cannot be realized due to lack of labor and insufficient funds. Second, overcapacity and lack of resources are common problems faced by various countries at different historical stages, and they cannot be solved only through internal allocation of the country. "The Belt and Road 
Initiative" has created the possibility for the optimal allocation of resources among cooperating countries. Third, it provides theories and methods for the balance of national development and global development. Due to factors such as geography and transportation, the development of some countries and regions is relatively backward and lacks the environmental conditions for rapid economic development. The "Belt and Road Initiative" can drive the flow of resources and capital in developed regions and remote and backward regions, thereby achieving effective economic development.

\subsection{Guide the West to pay attention to the contribution of China's "Belt and Road" to globalization, and enhance the causal cognition of vertical links}

"The Belt and Road" pursues open cooperation and is a "Chinese solution" under the background of globalization facing challenges. The initiative has played a positive and effective role in promoting the globalization process of countries in the world in different industries and fields. As of October 2018, the China-Europe Express trains under "the Belt and Road" construction departed from China to 44 cities in 15 European countries. The time for railway freight was about half compared with that of ocean freight, and the cost was also reduced by a third. The cost of bulk commodity transportation is significantly reduced, which greatly improves economic efficiency ${ }^{[1]}$. Since the launch of "the Belt and Road" Cultural Development Action Plan (2016-2020), China has held a series of large-scale cultural expositions, providing countries along "the Belt and Road" with a comprehensive exchange platform in culture, technology and other fields. According to estimates by relevant departments, during the 13th Five-Year Plan period, China will have 150 million visits to countries along the route, driving consumption of approximately US\$200 billion. At the same time, 85 million tourists from countries along the route travel to China, driving tourism consumption of approximately US\$110 billion. China's "The Belt and Road" achieves the overall maximization of global resource allocation. It does not take individual interests as the primary goal. It creates a peaceful, harmonious and harmonious atmosphere in the political, economic, military, cultural and other fields, in order to provide a realistic path choice for solving the current dilemma of globalization.

\subsection{Guide the West to pay attention to China's "Belt and Road" that is becoming a global consensus, and enhance the cognition of China's responsibility as a world power}

"The Belt and Road" is China's great practice in advancing "a community with a shared future for mankind". It is necessary to guide the West to pay attention to the concept of "a community with a shared future for mankind", "Chinese solutions", and "Chinese wisdom", and to understand the thinking and methods demonstrated in China's "Belt and Road" practice. The first is to carry out "Schematic" guidance to increase contact. More events such as summits and expos related to the "Belt and Road" should be held, and other countries should be encouraged to host or participate in the main activities of the "Belt and Road". This can strengthen exchanges and mutual learning between foreign cultures and deepen the awareness and understanding of "the Belt and Road" in other countries. The second is to lead the effect and enhance the experience. Every cooperative project of the "Belt and Road" is an image display window, and the China-Pakistan Economic Corridor is a concentrated display of "the Belt and Road" in the world. China has invested US\$62 billion in Pakistan through the China-Pakistan Economic Corridor for the construction of power stations, highways, railways and other projects. This has greatly eased the pressure on the transportation of fossil energy in the Middle East due to the Strait of Malacca, and effectively solved Pakistan's electricity, natural gas, and financial services. , Planting and a series of livelihood issues ${ }^{[2]}$. The third is to lead positively and increase awareness. Some Western scholars, politicians and media have misinterpreted the original intent of China's "Belt and Road" initiative. In particular, some Western developed countries have tried to hinder and suppress the rapid growth of the national power of developing countries, and have imposed trade protection, industry access, and technical barriers on developing countries. limit. We should make good use of international media tools to effectively refute and fight back against wanton smearing in a timely manner; actively influence and guide Western mainstream public opinion, vigorously promote the effectiveness of China in promoting the quality and upgrading of the "Belt and Road" construction; empower participating countries in "the Belt and Road" In the project, the Asian Infrastructure Investment Bank has more voice and decision-making power. Let the West realize that China's "Belt and Road Initiative" is developing in a broader and more global sense, and promote the formation of "a community with a shared future for mankind" as a universal cognition and willingness to act. 


\section{References}

[1] Tillman Henry, Jian Yang, Egill Thor Niels-son. The polar silk road: China's new frontier of international cooperation. China Quarterly of International Strategic Studies. 2018; 4(3): 349-351.

[2] Gu Shihong. Indonesian scholar Kuang Yaozhang: "The Belt and Road Initiative" has a positive impact on Indonesia. Available from: http://www.cio.gov.cn/m/31773/35507/35515/35523/Document/1530595/1530595.htm [Accessed 2019-10-04].

[3] Tiezzi S. The maritime silk road vs. the string of pearls. The Diplomat. 2014; (13): 104. 